\title{
A New Proposal Using a Turbine in the Reactor with a Cavitation System in the Biodiesel Synthesis
}

\author{
Sérgio L. Ferreira ${ }^{1}$ - Délson L. Módolo ${ }^{1} \cdot$ Vicente L. Scalon $^{1} \cdot$ Luiz E. A. Sanchez $^{1}$. \\ Elson Avallone ${ }^{3} \cdot$ Wagner L. Polito ${ }^{2}$
}

Received: 23 June 2016/Accepted: 29 September 2016/Published online: 3 October 2016

(C) Springer Science+Business Media Dordrecht 2016

\begin{abstract}
The present research investigates the effect of a cavitation system with a turbine in comparison to the vigorous stirring on the process of biodiesel synthesis by the transesterification reaction using oil (triglycerides) and anhydrous ethanol. The proposed cavitation equipment consists of a device that works as a turbine (novelty) and not by a pump. The turbine coupled to cavitation system showed a substantial degree of intensification in comparison to the conventional approach reported in the literature. An ester content of $96.4 \%$ in a 5 min reaction was obtained using conventional approach with vigorous stirring of $9500 \mathrm{rpm}$ and ethanol/oil molar ratio of $8: 1$ and $1.0 \mathrm{wt} \%$ catalyst concentration. An ester content of $98.5 \%$ was obtained using ethanol/oil molar ratio of $6: 1,1.0 \mathrm{wt} \%$ catalyst concentration and $60 \mathrm{~s}$ reaction by cavitation system with a turbine. The properties analyzed of biodiesel, such as density, viscosity, cetane number, cloud point, cold filter plugging point and flash point are within the limit values established by standard methods.
\end{abstract}

Keywords Biodiesel - Ester content · Turbine - Cavitation system $\cdot$ Electric consumption $\cdot$ Vegetable oil

Sérgio L. Ferreira

serggiolf@yahoo.com.br

1 Mechanical Engeneering Department, FEB, UNESP, 14 Eng. Luiz Edmundo C. Coube Avenue, Bauru, SP 17033-360, Brazil

2 São Carlos Institute of Chemistry University of São Paulo, 400 Trabalhador Saocarlense Avenue, São Carlos, SP 13560-970, Brazil

3 Federal Institute of Education, Science and Technology of São Paulo, 239 Pastor José Dutra de Moraes Avenue, Catanduva, SP 15808-305, Brazil

\section{Introduction}

Biodiesel is a mono-alkyl ester derived of long chain fatty acids from renewable sources such as vegetable oils or animal fats. Its use is associated with the replacement of fossil fuels in compression ignition engines [1, 2]. The transesterification process depends on the type of feedstock, kind and concentration of catalyst, amount of alcohol and the stirring level [3-5]. Currently, another factor that creates obstacles to the commercialization of biodiesel is its high cost. So much research is being done to minimize this cost of production $[6,7]$.

In a liquid-liquid heterogeneous system, the ultrasound equipment is very useful for improving mass transfer [8]. In this process, the cavities are created by the ultrasonic effect with enough energy to break off the molecules $[9,10]$. The phase boundary is changed by cavitation bubbles formed in the system, thus leading to a turbulent emulsification system in the transesterification process of vegetable oils with short chain alcohols [11].

Another technology is the use of hydrodynamic cavitation which can generally be defined as the generation, growth and subsequent collapse of the bubbles, resulting in high amounts of energy, temperatures and pressures [12]. Therefore, in the reaction process, free radicals generated by dissociation of vapor trapped in the cavitation bubbles result in intensification of chemical reactions under ambient conditions [11]. As mass transfer is a limiting factor in the transesterification process, intensification obtained in the reaction using a cavitating system depends on the number of cavitational events and reactor design [13, 14].

The present work reports on the application of a turbine in the reactor using a cavitation system to prepare biodiesel with more reduction of production costs. The proposed cavitation system using a turbine is a novel in the biodiesel 
synthesis via ethylic route. The results in the conventional biodiesel production process (CBPP) showed a reduction in electric consumption in function of the reaction time. Also, it is possible to observe a reduction in the reaction time in relation to CBPP using a turbine as cavitation system.

\section{Materials and Methods}

\section{Characterization of Soybean Oil}

The raw material used (soybean oil) was characterized by the determination of acid and iodine values, free fatty acids, saponification value, kinematic viscosity and water content. Table 1 shows the results of the analyses. The low free fatty acids, water content and other properties are within the limits established. According to Table 1 (iodine value), the fatty raw material has a high unsaturated degree. Moreover, the soybean oil used has good quality due to the low acid value.

\section{Biodiesel Production Processes}

\section{Procedure Using a Reactor with a Conventional Approach}

Refined soybean oil was used in this experiment. The reaction time started to be counted when the treated oil had been added to a fixed amount of a potassium hydroxide/ anhydrous ethanol solution prepared under vigorous stirring. When the reaction had reached the preset reaction time, the swirling was stopped. The products of reaction were allowed to settle overnight until the total separation of phases (biodiesel and glycerol). The optimal conditions used were $9500 \mathrm{rpm}$ (Fig. 3), 5 min reaction time, $1.0 \mathrm{wt} \%$ catalyst concentration and 8:1 ethanol/oil molar ratio (Figs. 4, 5, 6 respectively) for a high ester content in the biodiesel production process.

\section{Procedure Using a Reactor with a Cavitation System Coupled to a Turbine}

The experiments were performed by a cavitation system with a TECNAPE self-shear turbine to improve a reaction

Table 1 Physical and chemical characteristics of soybean oil

\begin{tabular}{ll}
\hline Physical and chemical properties & Soybean oil \\
\hline Acid value $(\mathrm{mg} \mathrm{KOH} / \mathrm{g})$ & 0.44 \\
Iodine value $\left(\mathrm{g} \mathrm{I}_{2} / 100 \mathrm{~g}\right)$ & 126 \\
Free fatty acids $(\%)$ & 0.009 \\
Kinematic viscosity at $40{ }^{\circ} \mathrm{C}\left(\mathrm{mm}^{2} \mathrm{~s}^{-1}\right)$ & 39.14 \\
Water content $\left(\mathrm{mg} \mathrm{kg}^{-1}\right)$ & 521.1 \\
Density at $20{ }^{\circ} \mathrm{C}\left(\mathrm{kg} \mathrm{cm}^{-3}\right)$ & 905.4 \\
\hline
\end{tabular}

mixture of refined soybean oil, anhydrous ethanol and $\mathrm{KOH}$ as catalyst in the biodiesel synthesis. Figure 1 shows a complete experimental set-up. Mechanical and sonic cavitations were used because the turbine emits strong ultrasonic waves into the reactor for the biodiesel production process. Figure 2 shows the components of the reactor, such as mechanical stirring (impeller), sensor to control the temperature, a vacuum pump, heating/cooling system and a cavitating turbine as an adjunct to the system of impeller. The turbine worked with a high-pressure inlet (up to $10 \mathrm{bar}$ ) and an outlet pressure of $1 \times 10^{-2} \mathrm{mmHg}$ (vacuum system of sealed reactor vessel). The main characteristic of the self-shear turbine used in the biodiesel production process was a molecular self-cleavage. Inert gas was injected into the turbine to guarantee a multiphaseheterogeneous system (gas, immiscible liquids). In the pipe of point (1) flows glycerol, recirculation water and small amount of catalyst and ethanol. At the point (2) flows glycerol, small amount of catalyst and water coming from the washing tank. At the point (3) flows only recirculation water. The point (4) represents the ethanol recovery pipe. The optimal conditions used were $1.0 \mathrm{wt} \%$ catalyst concentration (Fig. 5), 6:1 ethanol/oil molar ratio (Fig. 8) and $60 \mathrm{~s}$ reaction time (Fig. 7) for a high ester content in the biodiesel synthesis.

\section{Purification of FAEE (Fatty Acid Ethylic Ester)}

The crude ethylic ester phase was separated from the glycerol phase by a decantation funnel. Two distinct liquid phases were formed: a FAEE phase at the top and a glycerol phase at the bottom. The purification of ethylic ester was performed washing biodiesel with deionized water (until the water becomes clear) and a solution of citric acid $\left(0.01 \mathrm{~mol} \mathrm{~L}^{-1}\right)$ up to neutralization. Therefore, another contribution of the biodiesel purification was the utilization of a flash distillation system and recovery of anhydrous ethanol by rectification. The excess of water in the ester phase was removed by a rotary evaporator under ambient conditions. The ester content and other properties of FAEE were estimated under laboratory conditions. EN and ASTM methods were used for the biodiesel analysis.

\section{Results and Discussion}

\section{Effect of Vigorous Stirring in the Conventional Biodiesel Synthesis}

When the mechanical forces are used to move the mass for a particular chemical transformation, vigorous stirring produces disorders in the reactional system. It is possible to observe that the stirring parameter is not a limiting factor in 
Fig. 1 The complete experimental set-up in the biodiesel production process

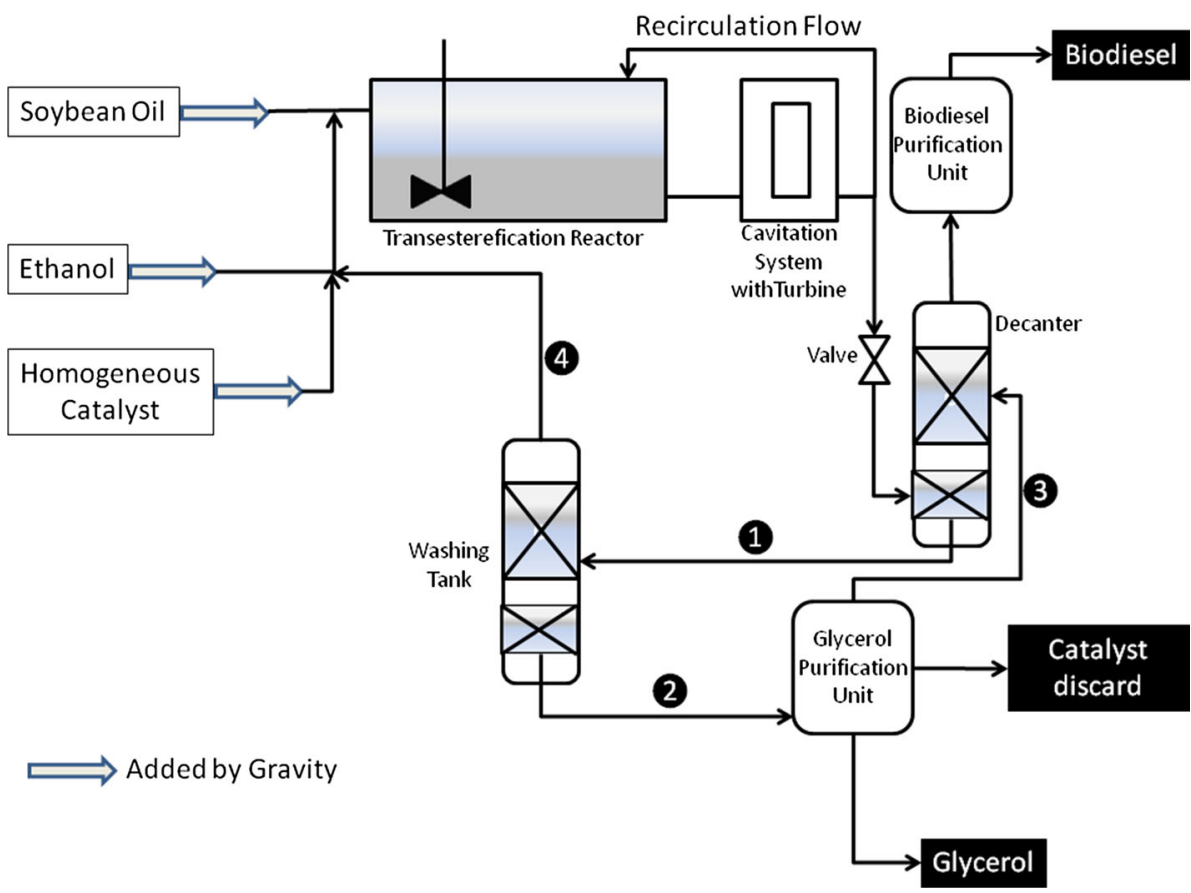

short reaction time with good quality. Equation (1) shows the relation between the Reynolds number and the stirring level [15]. The Reynolds number for the biodiesel synthesis should range from 6000 to 10,000 [16]. The higher the stirring, the higher the Reynolds number, i.e., a better distribution of mass transfer in the reactional system. The biodiesel synthesis is feasible in this Re range. Other important characteristic of the Reynolds number is to assist in design of the stirring system. This characteristic in the dispersed systems is relevant since for the biodiesel production, the aqueous phase is dispersed into a continuous phase and higher stirring condition ends up lower diameter of drops of the dispersed phase in the continuous phase.

$R e=\frac{(\mathrm{ID})^{2}(\mathrm{SL}) \rho}{60,000 \eta}$

where $R e$, Reynolds number; SL, Stirring level (rpm); 60,000 Empirical constant; $\eta$,Viscosity $\left(\mathrm{m}^{2} \mathrm{~s}^{-1}\right)$; ID-Inner diameter of the reactor $(\mathrm{m})$.

The drops have a proportional reverse diameter to the square root of the stirring speed Eq. (2) [17], therefore the higher the stirring speed, the smaller the drops and the faster the transesterification reaction. The concentration of drops in the suspended-immiscible phase increases in function of the reduction in the particle sizes, favoring the increase in the number of collisions per time unit. Materials, such as vegetable oils, animal fats and biodiesel have low superficial tension whereas the drops of the discontinuous phase (potassium ethoxide) have high superficial tension, facilitating the front collisions without scatterings of energy reflection and inhibiting coalescence. 
$d_{o}=K(S L)^{-2}$

where $d_{0}$, Diameter of the discontinuous phase drops (m); $\mathrm{K}$, Constant of the reactor; SL, Stirring level (rpm).

From the formation of potassium ethoxide to the addition of soybean oil, it is possible to observe that the molecular structure, polarity, interfacial tension and electrostatic forces influence solubility and miscibility in the biodiesel production process. The effect of a secondary structure of a molecule causes the boiling point of methanol to be lower than that of ethanol $\left(65\right.$ and $78{ }^{\circ} \mathrm{C}$, respectively), but the vapor pressures ( 98 and $43.9 \mathrm{mmHg}$ ) and ratios of evaporation (6 and 2.6) are higher for methanol [18]. The solubility parameter is higher for methanol (difference between methylic and ethylic alcohols was 1.38). Moreover, ethanol has a high parameter of fractional solubility associated with the London's dispersion and attractive polar forces. Polarity is higher for methanol due to the structure of the molecule and the inductive effects of this compound. Therefore, the interfacial tension among liquids has an important function in the preparation of potassium ethoxide and a more difficult dissolution of potassium hydroxide in ethanol is evidenced.

The effect of vigorous stirring on the conventional transesterification of the soybean oil was investigated varying this parameter from 1500 to $13,200 \mathrm{rpm}$ (Fig. 3). Figure 3 also shows the relation between ester content and stirring level. It is possible to observe that a good value of $96.4 \%$ for the ester content was obtained at $9500 \mathrm{rpm}$. The operation conditions during the whole reaction process were fixed at the optimal level: $9500 \mathrm{rpm}$ (Fig. 3), $5 \mathrm{~min}$ reaction time (Fig. 4), $1.0 \mathrm{wt} \%$ catalyst concentration (Fig. 5) and ethanol/oil molar ratio of 8:1 (Fig. 6). The conversion rate in ethylic esters depends on the reaction time. There occurred a reduction in the reaction time (6 times) by using vigorous stirring. Considering the

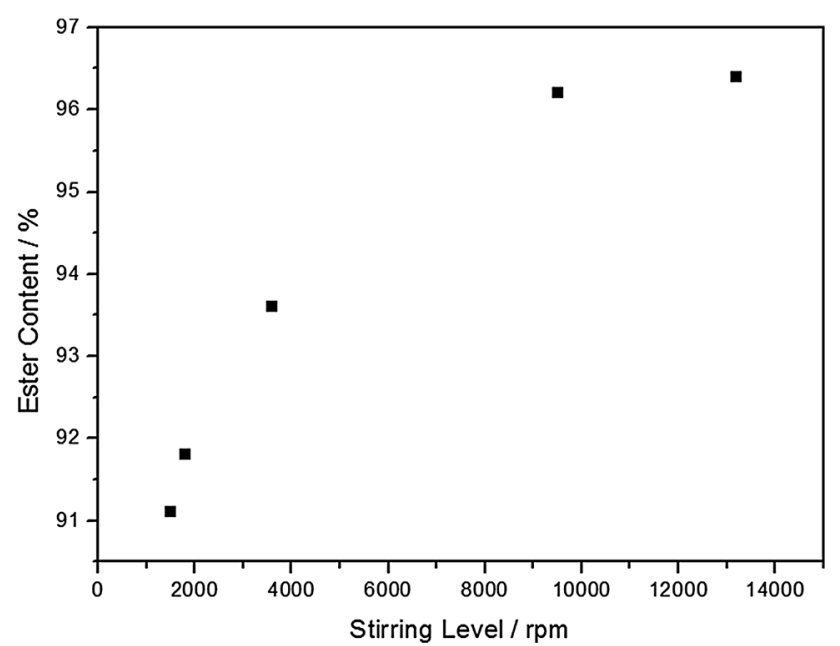

Fig. 3 Relation between ester content and stirring level

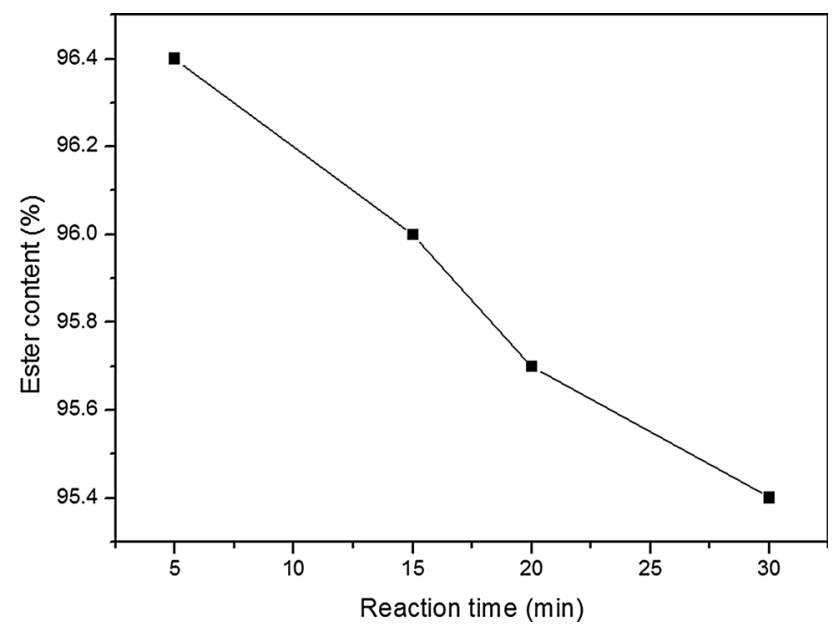

Fig. 4 Relation between ester content and reaction time using vigorous stirring

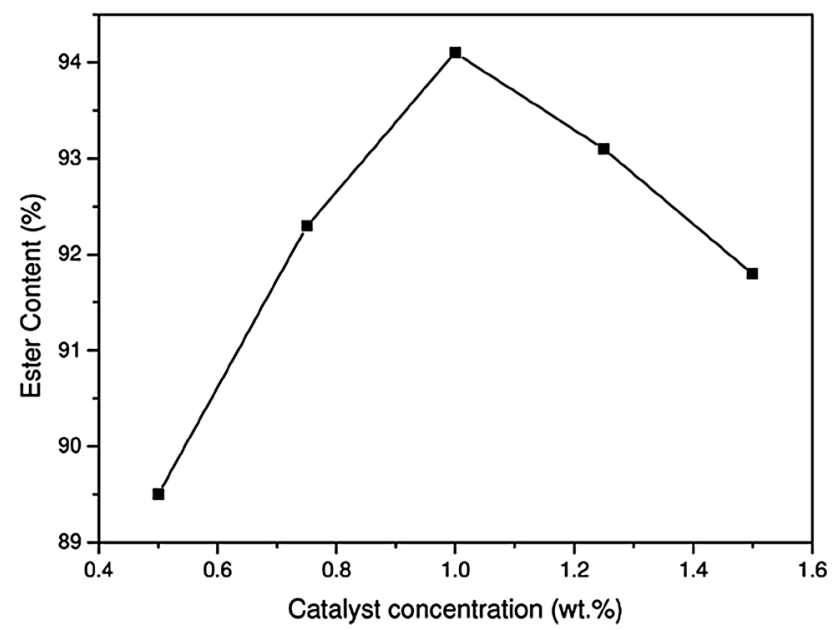

Fig. 5 Relation between ester content and catalyst concentration

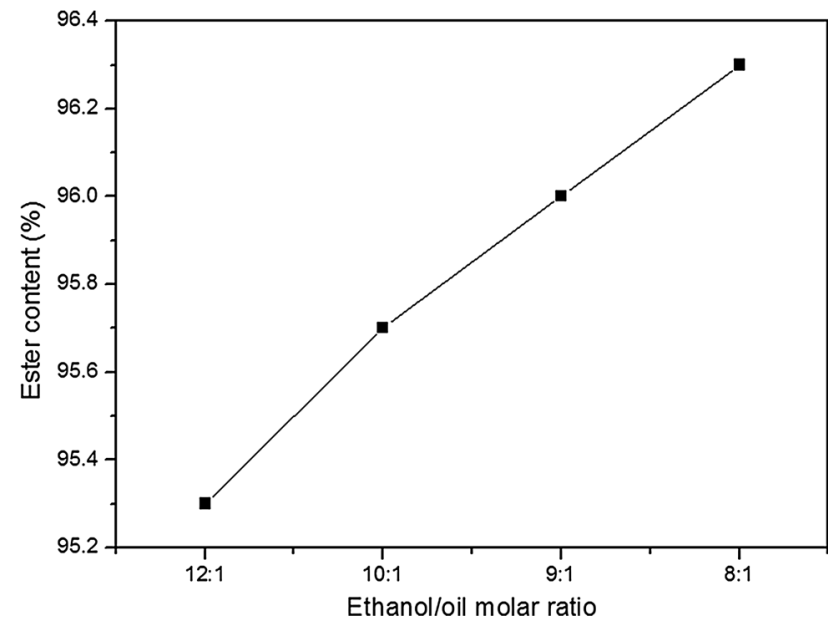

Fig. 6 Relation between ester content and ethanol/oil molar ratio using vigorous stirring 
Table 2 Relation between electric consumption and reaction time using vigorous stirring

\begin{tabular}{ll}
\hline Reaction time $(\mathrm{min})$ & $\begin{array}{l}\text { Electric consumption } \\
(\mathrm{kWh})\end{array}$ \\
\hline 5 & 0.041 \\
15 & 0.125 \\
20 & 0.166 \\
30 & 0.251 \\
\hline
\end{tabular}

calculation principles of electric power of a engine with a constant torque for the same mixing ratio and also the maximum nominal power observed in $13,200 \mathrm{rpm}$, it can be shown in Eq. (3) that::

$\frac{P 1}{P 2}=\frac{S L 1}{S L 2} \quad \frac{P 1}{0.7}=\frac{9,500}{13,200} \quad P 1=0.503 \mathrm{~kW}$

where $P 1$, Power at $9500 \mathrm{rpm}(\mathrm{kW}) ; P 2$, Maximum nominal power $(\mathrm{kW})$; SL1, stirring level with a good ester content of $96.4 \%$ (rpm); SL2, Maximum Stirring level (rpm).

Therefore 6 times less energy was consumed in the transesterification process in relation to reaction time (Table 2).

\section{The Influence of Using a Turbine in Cavitation System for Biodiesel Production}

An advantage of cavitation system is that it operates on a reduced scale and the collisions between oil and alcohol molecules occur quickly using narrow flow channels. The proposed device consists of a cavitation apparatus which works as a turbine and not a pump. The mechanical energy input in the cavitation system is generated by a high pressure of the flow input and a low pressure of the flow output. The turbine in the cavitation system works with a high-pressure flow on the output unlike the pumping in the cavitator. The cavitator system shown above uses a pump by which the material can flow. As the turbine system is self-propelled, it does not need a pumping system to assist the material flow.

The reaction is performed under extreme conditions using a turbine in the cavitator due to the turbulent flow. The reactants are submitted to cavitation in the reactor by appropriated impellers under vacuum conditions. The molecular cleavage occurs in the cavitator due to the opening and closing of small holes in the rotor. The macromolecules of triglycerides in vegetable oil are in contact with the micro-explosions produced under the effect of ultrasound, which enables the break' off chemical bonds and molecular rearrangements warranted a reduction in viscosity. The rotation values in the cavitator axes range from $10^{4}$ to $10^{6} \mathrm{rpm}$.
The proposed biodiesel synthesis was carried out via ethylic route. The turbine in the cavitation system provides the cavitation conditions of dispersion by a reduction in the ethanol and catalyst solution in the continuous phase (vegetable oil). This is a really significant improvement, since a turbine engine can be considered a special type of device to accelerate the transesterification reaction of vegetable oil with ethanol in the biodiesel production process. This methodology has not been cited in the literature.

The use of a turbine in the cavitating system proposed in this research showed a reduction in the reaction time from hours to seconds for the transesterification process. The optimal experimental conditions using this system were $60 \mathrm{~s}$ reaction time (Fig. 7), ethanol/oil molar ratio of 6:1 (Fig. 8) and $1.0 \mathrm{wt} \%$ catalyst concentration (Fig. 5). A reduction of 5 times in the reaction time using a turbine with a cavitation system was observed (Fig. 7).

\section{Physical and Chemical Characteristics of Biodiesel as Fuel for CI Engine}

There are several important properties of biodiesel that characterizes it like a fuel for compression ignition engines, such as density, viscosity, cetane number, cloud point, cold filter plugging point and flash point. The density of biodiesel is directly related to its molecular structure, therefore a longer chain contributes to a higher density. This density will be reduced in function of the increase in the unsaturations [19]. The density of diesel, biodiesel and biodiesel/diesel blends as fuels is an important property for the automotive industry, since the fuel injection system (injection pump and fuel injectors) introduces discrete volumes of fuel into the combustion chamber [20].

Thus, only with precise knowledge of the fuel density it is possible to calculate the total energy consumption by the

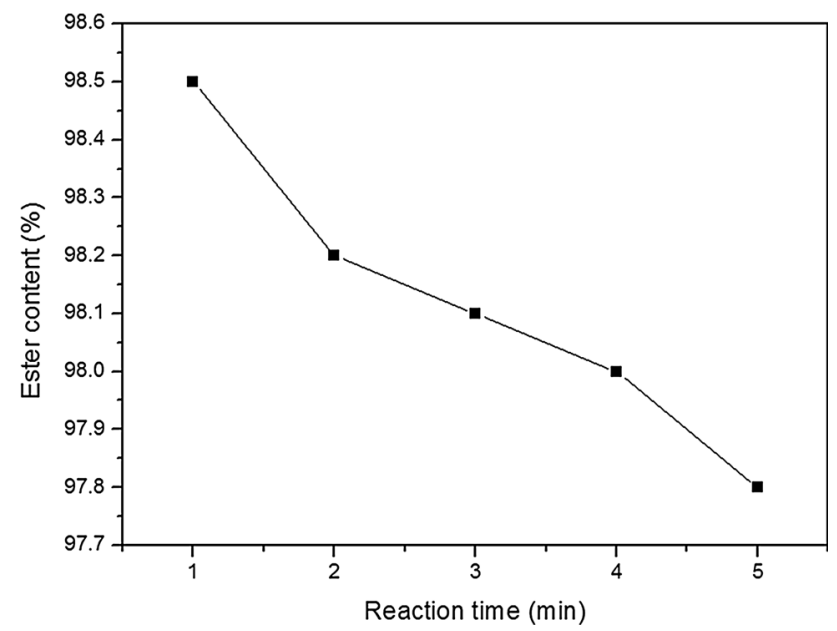

Fig. 7 Relation between ester content and reaction time using turbine 


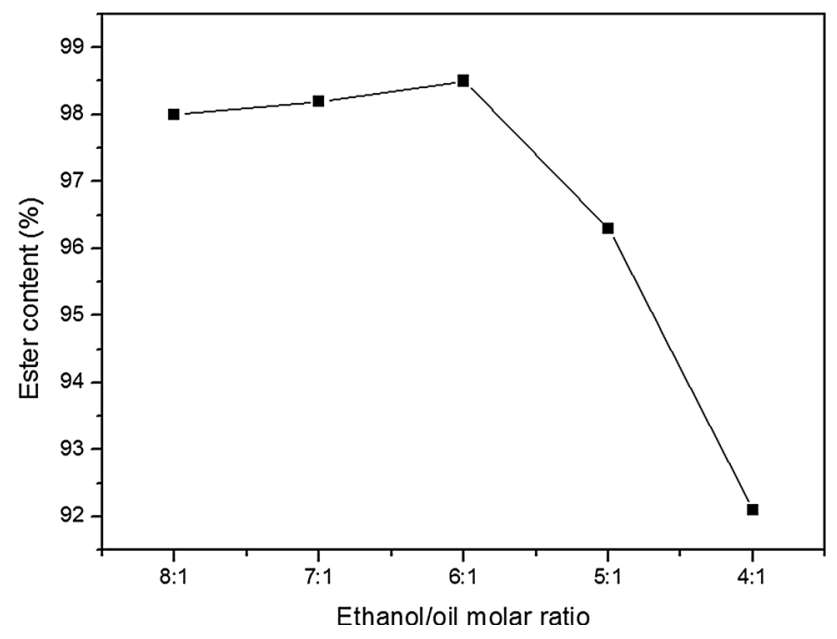

Fig. 8 Relation between ester content and ethanol/oil molar ratio using turbine

heating value of the fuel, which is often given as energy content per mass unit [21]. The density value for the biodiesel obtained in the experiment was $861 \mathrm{~kg} \mathrm{~m}^{-3}$, which is in accordance with the ASTM D1298 standard. An interesting comparison can be made between the densities of biodiesels and soybean oil. This parameter shows a reduction in the value for the biodiesel obtained in relation to the oil density.

Viscosity is a measure of the inner fluid friction or resistance of oil to flow in which this is an important factor for the oil flow through the pipelines, injector nozzles and orifices. This influences the fuel jet atomization mechanisms within the combustion chamber, i.e., the efficiency of the combustion process and the formation of residues in engine parts such as chambers, pistons, rings and as a consequence the lubricating oil contamination. As the temperature of oil increases, its viscosity decreases, and it is therefore able to flow more quickly. The viscosity is the most important property of biofuel since it affects the operation of fuel injection equipment, particularly at low temperatures in which the increase in viscosity affects the fuel fluidity [22]. Thus, biodiesel viscosity is a very important parameter for diesel engines.

Because biodiesel is a mixture of several fatty acid esters with each component contributing to the overall viscosity, it is possible to find the relation between viscosity and the content of fatty acid esters for the biodiesel fuel $[23,24]$. The kinematic viscosity of fatty esters is significantly influenced by the compound's structure. Influencing factors are chain length, position, number and nature of double bonds, as well as nature of oxygenated moieties [23]. In the present work, the data for kinematic viscosity are in good agreement with ASTM D445 standard for the analysis performed. The biodiesel obtained exhibits a viscosity value below $5 \mathrm{~mm}^{2} \mathrm{~s}^{-1}$, which is within the limit of ASTM D445 standard.

The cetane number $(\mathrm{CN})$ is the fuel's ability to ignite quickly after being injected into a CI engine. A better ignition quality of the fuel is always associated with a higher cetane number. A high $\mathrm{CN}$ implies short ignition delay. The longer carbon chains of the fatty acid and the more saturated the molecules, result in a higher $\mathrm{CN}$. The $\mathrm{CN}$ of biofuel from animal fats is higher than those from vegetable oils. Therefore, $\mathrm{CN}$ is an important parameter considered to FAEE for use as biodiesel [25].

The initial temperature of the oil crystallization which influences the feeding system negatively is the cloud point. This is an important property when the engine is started under conditions of low temperatures [25]. Generally, FAEE with a higher cetane number are favored for use as biodiesel. However, with an increase in the cetane number, the iodine value decreases (degree of unsaturation decreases), leading to the solidification of FAEE at lower temperatures [26].

The lowest temperature at which the fuel can pass through a filter is the cold filter plugging point. For the brazilian climate conditions, the value obtained $\left(4.5^{\circ} \mathrm{C}\right)$ was a good result for the biodiesel obtained. The flash point is the lowest temperature at which the fuel can vaporize to
Table 3 Physicochemical properties of the soybean biodiesel obtained as fuel for CI engine

\begin{tabular}{lll}
\hline Properties & Soybean biodiesel obtained as fuel for CI engine & Limits $^{\mathrm{a}}$ \\
\hline Density at $20{ }^{\circ} \mathrm{C}\left(\mathrm{kg} \mathrm{m}^{-3}\right)$ & 861 & $850-900$ \\
Kinematic viscosity at $40{ }^{\circ} \mathrm{C}\left(\mathrm{mm}^{2} \mathrm{~s}^{-1}\right)$ & 4.45 & $3.0-6.0$ \\
Cold filter plugging point $\left({ }^{\circ} \mathrm{C}\right)$ & 4.5 & 19 \\
Cloud point $\left({ }^{\circ} \mathrm{C}\right)$ & 12.0 & - \\
Acid value $(\mathrm{mg} \mathrm{KOH} / \mathrm{g})$ & 0.29 & 0.50 \\
Moisture content $\left(\mathrm{mg} \mathrm{kg}^{-1}\right)$ & 490.2 & 500 \\
Flash point $\left({ }^{\circ} \mathrm{C}\right)$ & 122 & 100 \\
Cetane number & 48 & - \\
Iodine value $\left(\mathrm{g} \mathrm{I}_{2} / 100 \mathrm{~g}\right)$ & 94.40 & - \\
\hline
\end{tabular}

${ }^{a}$ According to National Petroleum Agency (ANP-Brazil) 
form a flammable mixture with air by an external heat source. The flash point of biodiesel obtained was $122^{\circ} \mathrm{C}$, which makes it less volatile and safer in comparison to petrodiesel $\left(52{ }^{\circ} \mathrm{C}\right)$ [27].

High acidity can neutralize the basic catalyst; therefore, a larger quantity of catalyst is necessary for the reaction to be efficiently conducted. Moreover, a pronounced acidity affects the thermal stability of the fuel due to intermolecular reactions and causes a corrosive action on the metallic components of the engine [28]. Table 3 shows the physicochemical properties for the soybean biodiesel obtained in the experiments as a fuel for CI engines.

\section{Conclusions}

This work has provided great challenges and efforts for the development of biodiesel production via ethylic route. Good results for ester content were achieved using vigorous stirring and a turbine coupled to a cavitation system in the biodiesel production process. After several tests the best conditions obtained for ester content of $96.4 \%$ by vigorous stirring in the conventional biodiesel synthesis were $9500 \mathrm{rpm}$ and $5 \mathrm{~min}$ reaction time, $1.0 \mathrm{wt} \%$ catalyst concentration and ethanol/oil molar ratio of 8:1. Besides the influence of the stirring level, another important characteristic of the Reynolds number is to assist in design of the stirring system in the biodiesel production process. The parameters, such as the molecular structure, polarity, interfacial tension and electrostatic forces influence solubility and miscibility in the biodiesel synthesis. Vigorous stirring in the conventional biodiesel production reduced 6 times the reaction time (from 30 to $5 \mathrm{~min}$ ) and 6.12 times the electric consumption (from $0.251 \mathrm{kWh}$ to $0.041 \mathrm{kWh}$ ). The ester yield of $98.5 \%$ was obtained with a turbine in the cavitation system using ethanol/oil molar ratio of $6: 1$ in a $60 \mathrm{~s}$ reaction time and $1.0 \mathrm{wt} \%$ catalyst concentration. On the other hand, the use of a turbine in the cavitation system promoted a reduction of 5 times in the reaction time (from 5 to $1 \mathrm{~min}$ ). The properties analyzed of biodiesel, such as density, viscosity, cetane number, cloud point, cold filter plugging point and flash point are in accordance with the limit values established by standard methods.

Acknowledgments The authors are indebted to CNPq and CAPES for the financial support given to this research. They would also like to acknowledge the Center of Thermal and Fluids Engineering for the infrastructure supplied.

\section{References}

1. Ferreira, S.L., Santos, A.M., Souza, G.R., Polito, W.L.: Analysis of the emissions of volatile organic compounds from the compression ignition engine fueled by diesel-biodiesel blend and diesel oil using gas chromatography. Energy 33, 1801-1806 (2008)

2. Souza, G.R., Santos, A.M., Ferreira, S.L., Martins, K.C.R., Módolo, D.L.: Evaluation of the performance of biodiesel from waste vegetable oil in a flame tube furnace. Appl. Therm. Eng. 29, 2562-2566 (2009)

3. Furukawa, S., Uehara, Y., Yamasaki, H.: Variables affecting the reactivity of acid-catalyzed transesterification of vegetable oil with methanol. Bioresour Technol. 101, 3325-3332 (2010)

4. Santana, G.C.S., Martins, P.F., da Silva, N., Batistella, C.B., Maciel-Filho, R., Maciel, M.R.W.: Simulation and cost estimate for biodiesel production using castor oil. Chem. Eng. Res. Des. 88, 626-632 (2010)

5. Veljković, V.B., Avramović, J.M., Stamenković, O.S.: Biodiesel production by ultrasound-assisted transesterification: state of the art and the perspectives. Renew. Sustain. Energy Rev. 7, 1193-1209 (2012)

6. Chen, H., Chen, G.Q.: Energy cost of rapeseed-based biodiesel as alternative energy in China. Renew. Energy 36, 1374-1378 (2011)

7. Gog, A., Roman, M., Tosa, M., Paizs, C., Irimie, F.D.: Biodiesel production using enzymatic transesterification- current state and perspectives. Renew. Energy 39, 10-16 (2012)

8. Cravotto, G., Boffa, L., Mantegna, S., Avogadro, M., Perego, P., Cintas, P.: Improved extraction of natural matrices under highintensity ultrasound and microwave, alone or combined. Ultrason. Sonochem. 15, 898-902 (2008)

9. Stavarache, C., Vinatoru, M., Maeda, Y., Bandow, H.: Ultrasonically driven continuous process for vegetable oil transesterification. Ultrason. Sonochem. 14, 413-417 (2007)

10. Deng, X., Fang, Z., Liu, Y.H.: Ultrasonic transesterification of Jatropha curcas $L$. oil to biodiesel by a two-step process. Energy Convers. Manage. 51, 2802-2807 (2010)

11. Hanh, H.D., Dong, N.T., Okitsu, K., Nishmura, R., Maeda, Y.: Biodiesel production through transesterification of triolein with various alcohols in an ultrasonic field. Renew. Energy 34, 766-768 (2009)

12. Amin, L., Gogate, P.R., Burgessa, A.E., Bremner, D.H.: Optimization of a hydrodynamic cavitation reactor using salicylic acid dosimetry. Chem. Eng. J. 156, 165-169 (2010)

13. Sou, A., Maulana, M.I., Hosokawa, S., Tomiyama, A.: Cavitation in cylindrical nozzles and two dimensional nozzles. Int. J. Heat Mass Transf. 50, 3575-3582 (2007)

14. Andriotis, A., Gavaises, M., Arcoumanis, C.: Vortex flow and cavitation in diesel injector nozzles. Fluid Mech. 610, 195-215 (2008)

15. Amelio, A., Azhandeh, R., Darvishmanesh, S., Calabró, V., Degrève, J., Luis, P., Van der Bruggen, B.: Purification of biodiesel using a membrane contactor: liquid-liquid extraction. Fuel Process. Technol. 142, 352-360 (2016)

16. Lakshmi, C.V., Viswanath, K., Venkateshwar, S., Satyavathi, B.: Mixing characteristics of the oil-methanol system in the production of biodiesel using edible and non-edible oils. Fuel Process. Technol. 92, 1411-1417 (2011)

17. Ma, F., Clement, L.D., Hanna, M.A.: The effect of mixing on transesterification of beef tallow. Bioresour. Technol. 69, 289-293 (1999)

18. Polito, W.L.: A química dos materiais de revestimentos. São Carlos (2004)

19. Lôbo, L.P., Ferreira, S.L.C., Cruz, R.S.: Biodiesel: parâmetros de qualidade e métodos analíticos. Quim. Nova 32, 1596-1608 (2009)

20. Boudy, F., Seers, P.: Impact of physical properties of biodiesel on the injection process in a common-rail direct injection system. Energy Convers. Manage. 50, 2905-2912 (2009) 
21. Alptekin, E., Canakci, M.: Determination of the density and the viscosities of biodiesel-diesel fuel blends. Renew. Energy 33, 2623-2630 (2008)

22. Demirbas, A.: Biodiesel: a Realistic Fuel Alternative for Diesel Engines. Springer-Verlag, London (2008)

23. Rodrigues, J.A., Cardoso, F.P., Lachter, F.R., Estevao, L.R.M., Lima, E., Nascimento, R.S.V.: Correlating chemical structure and physical properties of vegetable oil esters. J. Am. Oil Chem. Soc. 83, 353-357 (2006)

24. Demirbas, A.: Relationships derived from physical properties of vegetable oil and biodiesel fuels. Fuel 87, 1743-1748 (2008)

25. Miraboutalebi, S.M., Kazemi, P., Bahrami, P.: Fatty Acid Methyl Ester (FAME) composition used for estimation of biodiesel cetane number employing random forest and artificial neural networks: a new approach. Fuel 166, 143-151 (2016)

26. Mejía, J.D., Salgado, N., Orrego, C.E.: Effect of blends of Diesel and Palm-Castor biodiesels on viscosity, cloud point and flash point. Ind. Crops Prod. 43, 791-797 (2013)

27. Balat, M.: Potential alternatives to edible oils for biodiesel production-a review of current work. Energy Convers. Manage. 52, 1479-1492 (2011)

28. Batista, A.D., Amais, R.S., Rocha, F.R.P.: Liquid-liquid microextraction in sequential injection analysis for the direct spectrophotometric determination of acid number in biodiesel. Microchem. J. 124, 55-59 (2015) 